\title{
Concepções de saúde mental a partir da análise do desenho de adolescentes
}

\author{
Cláudia Cristina Fukuda \\ Universidade de Brasilia \\ Karolyne Araújo Garcia \\ Hospital São Vicente de Paulo \\ Deise Matos do Amparo \\ Universidade de Brasília
}

\begin{abstract}
Resumo
Neste estudo buscou-se conhecer a percepção de saúde mental de adolescentes advindos de contextos socioeconômicos diferentes. Participaram da pesquisa 252 jovens do Distrito Federal, do Ensino Médio, sendo 129 de escola particular situada em região com alto Índice de Desenvolvimento Humano - IDH (54,3\% do sexo feminino, $34,1 \%$ do $3^{\circ}$ ano e $48,8 \%$ com idades acima de 16 anos) e 123 de escola pública situada em região de baixo IDH (52,8\% sexo feminino, $82,9 \%$ do $1^{\circ}$ ano e $32,8 \%$ com 16 anos). Solicitouse aos jovens que completassem, por meio de desenhos, a frase: "para mim, estar saudável mentalmente/ emocionalmente é...”. A análise dos desenhos resultou em 312 representações de saúde mental classificadas em 11 categorias temáticas. De forma geral, as representações de saúde mental estavam pautadas por uma visão ecológica, sendo representada principalmente por figuras humanas com conteúdos ligados a bem estar pessoal, representações de vínculos inter-relacionais e intrafamiliares e contextos sociais.
\end{abstract}

Palavras-chave: adolescência; concepções de saúde mental; desenhos; abordagem ecológica do desenvolvimento humano; contexto socioeconômico.

\begin{abstract}
Mental health conceptions out the youth's drawing analysis. This study aimed to investigate the mental health perception of teenagers from different socioeconomic backgrounds. A total of 252 students from the Federal District's High School, being 129 from private school located in a high Human Development Index (HDI) region $(54.3 \%$ female, $34.1 \%$ in the last year of high school and $48.8 \%$ aged over 16 years old) and 123 from public school located in a low HDI region $(52.8 \%$ female, $82.9 \%$ from the 1 st year of high school and $32.8 \%$ at the age of 16 ). The teenagers were asked to complete drawings by the phrase: "For myself, being mentally and emotionally healthy is ...". The analysis of drawings resulted in 312 mental health representations and 11 thematic categories. In general, the mental health representations were guided by an ecological view, represented mainly by human figures with related content to personal well-being, representations of inter-relational links and intra-family and social contexts.
\end{abstract}

Keywords: adolescence; conceptions of mental health; Ecology of Human Development; socio-economic conditions.

A adolescência, como uma fase do desenvolvimento humano, é perpassada por dificuldades relativas ao estabelecimento de conflitos e crises, caracterizada por mudanças dos aspectos biológico, psicológico, social e jurídico. Para abranger a amplitude desses aspectos, é necessária uma atenção integral ao adolescente, buscando a promoção de sua saúde. O uso de intervenções e estratégias adequadas, nessa fase, no campo da saúde, particularmente a mental, podem favorecer e direcionar a um desenvolvimento mais saudável com menor incidência de patologias e de fatores de risco social (Jones \& Peskin, 2010; Richter, 2006).

Estudos sobre saúde na adolescência cada vez mais têm se tornado emergentes em função dos fatores de risco e vulnerabilidade a que estão expostos os adolescentes, como violência, maus tratos, gravidez, adoecimento mental dentre outros aspectos que afetam sobremaneira o jovem nesse período do desenvolvimento (Amparo et al., 2008; Brasil, Alves, Amparo, \& Frajorge, 2006; De Antoni \& Koller, 2000; Heilborn et al., 2002; Pesce, Assis, Santos, \& Oliveira, 2005; Yunes, 2003).

De forma geral, as pesquisas sobre saúde e adolescência e, especificamente em saúde mental, têm como propósito a identificação e tratamento do problema, doenças físicas e psicológicas, desordem de conduta, problemas na escola, dentre outros fatores psicopatológicos e de vulnerabilidade (Bolsoni- 
Silva, Vilas Boas, Romera, \& Silveira, 2010; Jones \& Pesquim, 2010; Marques \& Cruz, 2000; Oliver et al., 2008; Pietro \& Tavares, 2005; Ritcher, 2006). Em tais pesquisas e nas que se referem às políticas públicas para essa fase do desenvolvimento, o adolescente é colocado em um papel de passividade e de vetor das influências biopsicossociais, havendo um distanciamento das vivências dos próprios adolescentes sobre sua saúde e bem-estar.

Para Piko e Bak (2006), conhecer as concepções de saúde e doença dos adolescentes é importante para o trabalho dos profissionais de saúde, sobretudo, num contexto sistêmico, no qual conhecer a perspectiva do adolescente e a sua rede de apoio possibilita a construção de serviços e políticas públicas personalizadas. Segundo Flick (2000), tais estudos não são frequentes na literatura, principalmente aqueles que consideram aspectos relacionados ao contexto cultural, diferenças sociais e individuais. Esta pesquisa traz uma contribuição específica com a caracterização de concepções sobre saúde mental na perspectiva de adolescentes de classes socioeconômicas distintas, advindos de contextos culturais e individuais diversificados.

A literatura mostra que a evolução histórica das concepções sobre saúde e doença deu origem a modelos específicos de atenção à saúde. Boruchovitch e Mednick (2002) apontam três visões principais de saúde a partir do século XX: o conceito médico, o conceito da Organização Mundial de Saúde (OMS) e o conceito ecológico.

O conceito médico define a saúde como ausência de doença, que é vista como mau funcionamento dos mecanismos biológicos, valorizando o aspecto orgânico, em detrimento de outros aspectos envolvidos no processo de adoecer (Koller \& Morais, 2006).

Com uma visão mais ampla, a Organização Mundial de Saúde-OMS propôs definir a saúde como "um estado completo de bem estar físico, mental e social e não apenas ausência de doença ou enfermidade" (Koller \& Morais, 2006, p. 73). Ao buscar atender a uma necessidade de ampliar a visão médica tradicional, concebe a saúde como um estado positivo de bem estar. Porém, essa definição apresenta alguns impasses, pois remete a uma ideia de um estado, de caráter estático, de completo bem estar, o que é praticamente inviável.

Ao se atribuir à saúde um conceito mais holístico, dando ênfase na interação do ambiente e a qualidade de vida das pessoas, surge a visão ecológica. Nesta visão o conceito de saúde foi definido por Boruchovitch e Mednick (2002) como "a capacidade funcional adequada que permite à pessoa realizar suas obrigações e responsabilidades, ou em termos de certa qualidade de vida que o permite viver feliz, com sucesso, de forma frutífera e criativa" (p. 176). Vale destacar que na visão ecológica a saúde é considerada multidimensional, sendo que um conceito universal é inatingível.

Para Koller e Morais (2006), as concepções de saúde possuem lacunas devido ao caráter reducionista, impreciso e relativo de seus conceitos. Ao buscar uma visão mais abrangente das concepções de saúde, vários autores ressaltam aspectos fundamentais nas suas definições. Minayo (2008) afirma que saúde e doença são fortemente influenciadas pelo contexto cultural e pelos estados afetivos em que ocorrem. Nessa mesma perspectiva, Boddington e Räisänem (2009) consideram que a definição de saúde e doença varia tanto interculturalmente quanto intraculturalmente. Para outros autores, a visão de saúde e doença condiciona a forma como cada pessoa experimenta seus estados de saúde e de doença, os comportamentos adotados para evitar a doença ou restabelecer a saúde e, inclusive, as próprias práticas de atendimento à saúde (Flick \& Röhnsch, 2007; Tontas, 2009).

Ao avançar nessa perspectiva, Koller e Morais (2004) resgatam a concepção de saúde/doença como um processo inerente à existência humana, fazendo parte de um mesmo continuum no decorrer do processo evolutivo. Características do contexto sociocultural na definição de práticas ditas saudáveis ou não, somados aos aspectos psicológicos, sociais e espirituais, além da divisão clássica entre mente e corpo, devem ser considerados como influências para a construção do conceito de saúde. Pode-se perceber que nessa abordagem há relação entre desenvolvimento e saúde, como resultante de um processo de interação contínua entre a pessoa e o seu contexto. A existência de relações recíprocas, baseadas no afeto e equilíbrio de poder pode gerar um desenvolvimento saudável.

Essa concepção de saúde é coerente com o modelo da abordagem ecológica do desenvolvimento humano de Bronfenbrenner (1986; 1989; 1996), que tem embasado pesquisas norteadas por uma visão de pessoa como ser integrado e em troca constante com o contexto. Ao caracterizar essa abordagem, Bronfenbrenner propôs o estudo do desenvolvimento humano a partir da interação de quatro núcleos: processo, pessoa, contexto e tempo.

Neste modelo, o desenvolvimento humano é compreendido com um processo onde ocorrem mudanças estáveis nas pessoas devido à interação com o ambiente. Para o autor: "O desenvolvimento humano é o processo através do qual a pessoa desenvolvente adquire uma concepção mais ampliada, diferenciada e válida do meio ambiente ecológico, e se torna mais motivada e mais capaz de se envolver em atividades que revelam suas propriedades, sustentam ou reestruturam aquele ambiente em níveis de complexidade semelhante ou maior de forma ou conteúdo" (Bronfenbrenner, 1996, p. 23). Sua concepção privilegia os aspectos saudáveis do desenvolvimento, que estão relacionados ao envolvimento e interação da pessoa biopsicologicamente em evolução, no maior número possível de ambientes e em contato com diferentes pessoas.

No modelo bioecológico o processo é o principal mecanismo de desenvolvimento. Bronfenbrenner (1996) chamou de processos proximais a interação recíproca da pessoa com objetos e outras pessoas, no seu ambiente imediato. Essa interação possibilita o desenvolvimento de competências e disfunções, que podem ser capazes ou não de controlar, conduzir e manter integrado o comportamento.

A pessoa, como segundo componente do modelo ecológico, é analisada a partir de suas características biopsicológicas e das construídas em interação com o ambiente. São as disposições (características pessoais), os recursos (deficiências ou atributos psicológicos) e a demanda (os atributos pessoais), que são vistos como mediadores de estabilidade e mudanças de suas características biopsicológicas, sendo produto e produtoras do desenvolvimento (Koller \& Morais, 2006).

O terceiro componente do modelo ecológico, o contexto, 
é analisado através da interação de quatro níveis ambientais: microssistema, mesossitema, exossistema e macrossistema. $\mathrm{O}$ microssistema é formado pelas atividades, papéis e relações nos variados ambientes. O mesossitema é o conjunto de microssistemas que a pessoa frequenta e as inter-relações estabelecidas neles, por exemplo, a interação entre a família do adolescente e a escola. O exossistema é o ambiente que a pessoa não frequenta como participante ativo, mas que influencia indiretamente seu desenvolvimento, como o trabalho dos pais ou a Secretaria de Educação. E o macrossistema é formado pelas ideologias, crenças, valores, religiões, formas de governo que se comunicam com os sistemas (Bronfenbrenner, 1996).

O tempo, que é o quarto componente do modelo ecológico, é um sistema integrado, denominado cronossistema, que se divide em microtempo, mesotempo e macrotempo, e refere-se à relação das pessoas com os acontecimentos presentes, os mais antigos em relação aos mais próximos e a acontecimentos históricos (Koller \& Morais, 2006).

A adolescência, na teoria ecológica, é o tempo em que a pessoa amplia sua interação com o ambiente sendo influenciada e influenciando-o. Pereira (2005) afirma que o adolescente se desenvolve dentro de ambientes sociais que incluem a família, a comunidade e as sociedades, também sendo influenciado pela cultura através dos meios de comunicação e mídia.

Compreende-se que mesmo não se referindo diretamente à saúde e/ou à doença na adolescência, essa abordagem contribui para a compreensão desses conceitos e foi contemplada neste estudo, pois se considera que saúde e doença são produtos da interação recíproca da pessoa com o meio, e o resultado dessa interação pode promover um desenvolvimento saudável.

Visando contribuir para a compreensão da percepção de saúde/doença na adolescência, essa pesquisa buscou conhecer a noção de saúde mental de adolescentes a partir de suas perspectivas, experiências, mitos e concepções, exploradas por meio de seus desenhos e representações gráficas. Considerase que dentro os vários aspectos relacionados à saúde do adolescente, o que se refere especificamente à saúde mental é o mais negligenciado, tanto nos serviços de saúde oferecidos quanto nas políticas públicas de atenção à adolescência.

\section{Método}

O presente trabalho consistiu em um estudo exploratório das concepções e significados de saúde/doença de adolescentes, advindos de contextos socioeconômicos diferentes, analisados a partir de seus desenhos.

Considerando o desenho como uma linguagem, Moreira (2008) afirma que este é um meio simbólico de comunicação e expressão de conteúdos subjetivos, com a intenção de dizer algo, de contar de si. Segundo Goldberg, Yunes e Freitas (2005), o desenho ajuda a criança a organizar seu mundo interno e sua análise permite acessar a percepção do indivíduo sobre os ambientes externos. Muito do que os adolescentes pensam está influenciado pelo olhar do outro (Kaplan \& Sadock, 1984). Dessa forma, a utilização do desenho como técnica gráfica e, portanto, menos sujeita a desejabilidade social, é apropriada para a análise da percepção do adolescente acerca da saúde mental, pois manifesta e explicita a concepção do indivíduo a partir de suas experiências e representações temáticas. Portanto, tendo acesso ao conteúdo e temas das representações gráficas trazidas pelos adolescentes sobre saúde mental, é possível compreender os significados de suas percepções de forma mais fidedigna.

\section{Participantes}

Os participantes da pesquisa pertenciam a dois grupos distintos. O primeiro grupo (Grupo 1), foi constituído por 129 jovens estudantes do Ensino Médio de uma escola particular do DF situada em região urbana com alto Índice de Desenvolvimento Humano (IDH). Destes, 43 (33,3\%) estavam no primeiro ano, 40 (31\%) no segundo ano e 44 (34,1\%) no terceiro ano, 2 (1,6\%) não informaram sua escolaridade. Em relação ao sexo, 70 (54,3\%) eram do sexo feminino e $59(45,7 \%)$ do masculino. Quanto à idade verificou-se que um jovem tinha 14 anos, $22(17,1 \%)$ tinham 15 anos, $42(32,6 \%)$ tinham 16 anos e 63 (48,8,\%) tinham 17 anos ou mais. Um jovem não informou a idade.

O segundo grupo (Grupo 2), foi formado de 123 jovens estudantes do Ensino Médio de duas escolas públicas do DF localizadas em região urbana de baixo IDH. Em relação ao sexo, $65(52,8 \%)$ eram do sexo feminino e $58(47,2 \%)$ do masculino. Estavam no primeiro ano $102(82,9 \%)$ jovens e apenas $3(2,4 \%)$ no segundo ano, sendo que $18(14,6 \%)$ jovens não informaram sua escolaridade. Quanto à idade, $13(10,7 \%)$ jovens tinham 14 anos, 39 (32\%) tinham 15 anos, 40 (32,8\%) tinham 16 anos e $27(22,1 \%)$ tinham 17 anos ou mais e $3(2,5 \%)$ jovens não informaram a idade.

As escolas foram selecionadas por conveniência, considerando-se o critério de localização segundo o IDH. As salas de aula foram indicadas pelas escolas de acordo com a série e a idade dos estudantes, todos os adolescentes das salas indicadas foram convidados a participar da pesquisa.

\section{Instrumento}

Para acessar as concepções de saúde mental dos jovens utilizou-se a representação gráfica no formato de desenhos e fragmentos de textos escritos contidos nos desenhos feitos pelos adolescentes sobre o que, na sua percepção, representava saúde mental. As representações gráficas foram obtidas a partir da quinta parte de um questionário que estava inserido em um contexto de uma pesquisa mais amplo e foi adaptado para o Brasil por Morais (2008) do original desenvolvido por Käppler, Gonçalves, Peng e Anastasi (2004, citado por Morais, 2008). O questionário era composto de 172 itens, divididos em cinco partes: Saúde, Família, Bem Estar, Condições de Vida e Representação Gráfica de Saúde Mental. Nesta pesquisa foram utilizadas as duas últimas partes.

\section{Procedimentos de coleta de dados}

Após contato com as Escolas, a concordância das mesmas em participar da pesquisa e a indicação da sala de aula e do dia e horário para a aplicação do questionário, na escola particular, foi solicitado aos estudantes que levassem para seus pais ou responsáveis o Termo de Consentimento Livre e Esclarecido (TCLE) e que fossem devolvidos na escola até o dia da coleta dos dados. Nas escolas públicas, os pais foram informados 
da pesquisa e solicitados a assinar o TCLE durante reunião pedagógica de pais e professores.

$\mathrm{Na}$ escola particular foi indicada uma turma de cada ano do Ensino Médio do período matutino; já nas escolas públicas foi indicada apenas uma turma matutina do primeiro ano do Ensino Médio por escola, sendo assim, necessárias duas escolas para integralização e equiparação do tamanho da amostra.

A coleta de dados foi realizada em aplicação coletiva, em sala de aula, no período matutino e teve duração de uma aula (50 minutos). Foi feita apresentação da pesquisa para os adolescentes e, para aqueles que aceitaram participar da pesquisa, foi solicitado que assinassem o TCLE e que respondessem ao questionário, bem como realizassem o desenho, parte referente a este estudo. A pesquisa foi aprovada pelo Comitê de Ética (ofício CEP/UCB 86/2006).

$\mathrm{Na}$ fase da representação gráfica foi solicitado oralmente aos jovens que completassem, utilizando a folha em branco que se encontrava na última página do questionário, por meio de desenhos a frase: "para mim, estar saudável mentalmente/ emocionalmente é..."

\section{Procedimentos de análise de dados}

Todos os desenhos produzidos pelos participantes foram tratados pelas pesquisadoras a partir de análise para identificar desenhos com conteúdos próximos. Após a identificação do conteúdo, eles foram agrupados em categorias de acordo com a proximidade dos conteúdos expressos nos desenhos. Para ajuizar se as categorias elaboradas estavam adequadas às representações e significados dados pelos jovens acerca de saúde mental, realizou-se uma análise de juízes. Participaram da análise de juízes três estudantes e três professores de graduação em psicologia.

Para a análise de juízes, os desenhos foram agrupados aleatoriamente em três blocos, de 84 desenhos. Cada bloco de desenhos foi analisado por dois juízes (um estudante e um professor), que receberam a instrução de analisar o desenho como um todo e classificá-lo em categorias. Porém, desenhos com vários conteúdos que, na percepção deles, não formavam uma única ideia, poderiam ser classificados em mais de uma categoria. Além disso, novas categorias poderiam ser sugeridas. Tais análises foram realizadas pelo preenchimento de um protocolo para a análise de juízes, onde era especificada a categoria e suas definições. Os juízes não foram informados sobre quais eram as categorias originais dos desenhos.

O desenho foi mantido numa categoria no caso de duas concordâncias, considerando os juízes e a categorização original. No entanto, em caso de discordância entre os juízes com relação à categoria inicial, os desenhos foram classificados em outra categoria de concordância. Nenhum desenho foi classificado diferentemente da categoria original e ao mesmo tempo em categorias diferentes pelos juízes.

Dos 252 desenhos analisados pelos juízes, 241 foram mantidos nas categorias elaboradas previamente e 11 mudaram de categoria. Duas novas categorias foram sugeridas, porém, pelo pequeno número de desenhos classificados nessas categorias, optou-se por ampliar as definições de categorias já existentes. Para verificar se as frequências de ocorrência de uma categoria eram significativamente diferentes nos contextos de alto e baixo IDH, utilizou-se análise de qui-quadrado $(p<0,10)$.

\section{Resultados e discussão}

Os desenhos foram agrupados em 11 categorias, enumeradas de 1 a 11 , sendo que uma das categorias foi dividida em 4 subcategorias. As categorias encontradas foram:

(1) Bem estar consigo mesmo e autoestima: figuras humanas representando sentimentos de harmonia e felicidade; pensamento positivo; autoconfiança; aceitação de si; disposição para aprender ou exercer algo;

(2) Bem estar na relação com o outro

(2.1) Bem estar na relação com o outro não definido: figuras humanas representando boas relações, vínculos, bom humor, sorrisos, sentimentos de felicidade, harmonia, alegria e união em interação com outras pessoas ou grupos não definidos.

(2.2) Amor e relacionamento afetivo: figuras em casal, díade homem e mulher, ou figuras em formato de coração ou palavra "amor" sem nenhuma outra especificação.

(2.3) Família: figuras humanas representando uma unidade grupal onde se percebe relações de pais/filhos/irmãos

(2.4) Amigos: figuras humanas definidas como amigo (a) representando interação, bem estar e/ou aceitação pelos pares.

(3) Sentimento de paz, liberdade e harmonia global: figuras humanas em contextos de natureza, campo, globo terrestre; frases, símbolos ou palavras que remetem a ideia de paz e liberdade.

(4) Esportes e lazer: figuras humanas em interação, desenvolvendo atividades prazerosas ou esportes (balé, futebol, brincadeiras).

(5) Escola: figura representando uma escola ou palavras que remetem à escola, tal como a palavra estudo.

(6) Contextos sociais: figuras humanas podendo representar ou não pessoas de referência (amigos, pais, etc.) com acréscimo de pelo menos dois ambientes (tais como escola, igreja, casa) e/ ou situações (emprego, lazer, atividades físicas)

(7) Adoecimento físico/mental: figuras humanas com humor triste e que representem limitações físicas ou problemas psicológicos.

(8) Violência: figuras humanas que sofriam algum tipo de discriminação, preconceito ou objetos que remetem a ideia de violência física, por ex: revólver.

(9) Fé e religião: figuras humanas representando bem estar ligado ao pensamento em Deus, Igreja e fé.

(10) Saúde do corpo e equilíbrio pessoal (mente /corpo): saúde mental ligada à ideia da saúde do corpo e equilíbrio mente/ corpo, formada por desenhos de figuras humanas representando preocupações com o corpo, alimentação, bem estar físico e objetos como balança, representando equilíbrio entre emoções e o aspecto físico.

(11) É algo complexo ou indefinido: desenhos que contenham frases pontuando que saúde mental é algo complexo ou difícil de definir, figuras como interrogação ou abstratas, além de figuras não definidas, com conteúdo adverso.

A Tabela 1 apresenta a frequência em que as categorias foram identificadas nos desenhos. É importante destacar que o 
número de desenhos foi maior em relação ao número de jovens, justificado pela classificação de desenhos com vários conteúdos, que não formaram uma única ideia, em mais de uma categoria. Assim, verificou-se que foram expressos pelos desenhos 170 $(54,5 \%)$ representações de saúde mental no Grupo 1 e 142 $(45,5 \%)$ no Grupo 2.
Para o Grupo 1, a representação de saúde mental está ligada, em ordem de ocorrência, principalmente às categorias Bem estar consigo mesmo e autoestima (26,4\%), Família (16,4\%) e Amigos (12,9\%). Para o Grupo 2, as categorias que ocorreram com maior frequência foram: Bem estar consigo mesmo e autoestima (23,2\%); Esportes e lazer (12,6\%); Família (11,2\%)

Tabela 1

Frequência de desenhos dos adolescentes sobre saúde mental por categoria

\begin{tabular}{|c|c|c|}
\hline \multirow{2}{*}{ Categorias: Saúde mental ligada às ideias de: } & Grupo 1 & Grupo 2 \\
\hline & $N(\%)$ & $N(\%)$ \\
\hline $\begin{array}{l}\text { (1) Bem-estar consigo mesmo e autoestima } \\
\text { (2) Bem-estar na relação com o outro }\end{array}$ & $45(26,4 \%)$ & $33(23,2 \%)$ \\
\hline (2.1) Bem-estar na relação com o outro não definido. & $13(7,6 \%)$ & $13(9,15 \%)$ \\
\hline (2.2) Amor e relacionamento afetivo & $8(4,7 \%)$ & $14(9,8 \%)$ \\
\hline (2.3) Família & $28(16,4 \%)$ & $16(11,2 \%)^{*}$ \\
\hline (2.4) Amigos & $22(12,9 \%)$ & $9(6,3 \%)^{* *}$ \\
\hline (3) Sentimento de paz, liberdade e harmonia global. & $10(5,8 \%)$ & $9(6,3 \%)$ \\
\hline (4) Esportes e lazer & $11(6,4 \%)$ & $18(12,6 \%)$ \\
\hline (5) Escola & $6(3,5 \%)$ & $1(0,7 \%)$ \\
\hline (6) Contextos sociais & $12(7,05 \%)$ & $4(2,8 \%)^{* *}$ \\
\hline (7) Adoecimento físico/mental & $1(0,6 \%)$ & $7(4,9 \%)$ \\
\hline (8) Violência & - & $3(2,1 \%)$ \\
\hline (9) Fé e religião & $5(2,9 \%)$ & $7(4,9 \%)$ \\
\hline (10) Saúde do corpo e equilíbrio pessoal (mente /corpo) & $3(1,7 \%)$ & $7(4,9 \%)$ \\
\hline (11) É algo complexo ou indefinido & $6(3,5 \%)$ & $1(0,7 \%)$ \\
\hline TOTAL & 170 & 142 \\
\hline
\end{tabular}

* Diferenças significativas pela análise do qui-quadrado $(p<0,10)$

** Diferenças significativas pela análise do qui-quadrado $(p<0,05)$

e Bem-estar na relação com o outro não definido $(9,15 \%)$. Para este grupo a categoria Amigos (6,3\%) aparece em sexta posição. Como possível justificativa para essa diferença na categoria Amigos considera-se o fato de uma menor ocorrência de identificação (como amigos, famílias, professores etc.) das figuras humanas desenhadas pelo Grupo 2, o que explica também a maior incidência da categoria Bem-estar na relação com o outro não definido.

Comparando jovens dos grupos 1 e 2, pode-se perceber diferenças significativas quanto à concepção de saúde mental dos jovens, que perpassam os significados Família, Amigos e Contextos Sociais. Identificou-se uma maior incidência da categoria Família nos desenhos de jovens provenientes de região com alto IDH (Grupo 1) em relação àqueles provenientes de regiões com baixo IDH (Grupo 2) $\left(\chi^{2}=3,27 ; p<0,10\right)$. O mesmo ocorrendo para a categoria Amigos $\left(\chi^{2}=4,45 ; p<0,05\right)$ e Contextos sociais $\left(\chi^{2}=4,00 ; p<0,05\right)$.

Apesar das diferenças encontradas nos grupos, considera-se que para os dois grupos a influência dos pares foi importante para a caracterização de saúde mental. A categoria Amor e relacionamento afetivo (Grupo $1-4,7 \%$ e Grupo $2-9,8 \%$ ) reforça a importância dada pelos jovens aos pares, conforme assinalado por Pereira (2005) e outros autores (Marques \& Cruz, 2000; Sudbrack \& Pereira, 2003).

A categoria Contextos sociais ocorreu com maior frequência nos desenhos dos jovens do Grupo 1 em contraposição aos participantes do Grupo 2. Assim, os jovens do Grupo 1 apresentaram com maior frequência uma visão mais ampla acerca da temática, permeada pela interação da pessoa em mais de um ambiente do seu contexto individual. Já os jovens do Grupo 2 representaram a interação pessoa/ambiente em microssistemas separados, visto que as categorias Esporte e lazer e Fé e religião ocorreram com maior frequência neste grupo que no grupo Contextos sociais.

Entende-se que é benéfico estar em interação com outras atividades e grupos, além de desenvolver atividades prazerosas. À luz da teoria ecológica, esse processo de socialização promove desenvolvimento. Percebem-se as categorias: Esporte e lazer; Fé e religião; e Escola como microssistemas, consolidados e de novas relações, além de demonstrar a ampliação de papéis específicos dentro do contexto desses jovens. Essas categorias podem refletir ideias sobre dois elementos importantes do modelo ecológico, pessoa e contexto, que em interação podem promover o desenvolvimento saudável.

Em relação às demais categorias, não foram constatadas diferenças significativas. Porém, algumas dessas diferenças foram consideradas relevantes devido ao seu conteúdo. No Grupo 2, obteve-se representações de saúde mental por meio de figuras humanas que sofriam algum tipo de discriminação ou preconceito, ou objetos que remetiam a ideia de violência física, 
por ex: revólver. Essa categoria denominada Violência, apareceu em 2,1\% dos desenhos desse grupo e não foi identificada nas representações dos jovens do Grupo 1, deduzindo-se que estes não fizeram a ligação entre as ideias de violência e a temática saúde mental. Pontua-se que mesmo com a frequência baixa de desenhos que remetem a ideia de violência, essa categoria é válida e importante para a percepção de alguns jovens do Grupo $2(2,1 \%)$, visto que apenas esse grupo a mencionou. Tem-se como hipótese que por viverem em regiões de baixo IDH e sujeita a maiores índices de violência e vulnerabilidade social, torna este contexto influência na concepção de saúde mental. Infere-se que essa visão acerca da saúde mental é uma forma de percebê-la como encoberta de preconceitos, na exclusão do que é "problemático", seja pela via da discriminação ou pela via da agressão física. Atribuiu-se à saúde mental conteúdo negativo, ainda que associado ao contexto. Observaram-se, também, no Grupo 2 sete desenhos que caracterizaram a saúde mental como relacionada a Adoecimento fisico/mental e em apenas um desenho do Grupo 1 esse significado apareceu. Considerando saúde numa perspectiva holística infere-se que o contexto de baixo IDH, no qual as condições sociais de bem-estar e de subsistência são precárias, pode ter influenciado negativamente a percepção dos jovens em relação à saúde mental.

De forma geral, apareceram nos desenhos representações pautadas por uma visão ecológica acerca do tema saúde mental. Sob uma perspectiva mais positiva, os jovens conceberam a saúde mental com representação de figuras humanas com conteúdos ligados a bem estar pessoal, representações de vínculos inter-relacionais e intrafamiliares, contextos sociais e saúde do corpo, em contraposição a aspectos que podem ser considerados negativos, perpassados pelas ideias de saúde mental ligado a adoecimento físico/mental e violência, que ocorreram com maior frequência no Grupo 2.

Tendo em vista que, historicamente, a tendência de muitos trabalhos relacionados à adolescência e à saúde mental tem como propósito a identificação do problema, da psicopatologia, da doença e do desvio, influenciados pelo modelo biomédico (Boruchovitch \& Mednick, 2002), observou-se na pesquisa em questão que, apesar de saúde mental ter sido algumas vezes expressa por desenhos característicos de um modelo biomédico identificado nas categorias: Adoecimento fisico/mental (Grupo 1, $0,6 \%$ e Grupo 2, 4,9\%) e Saúde do corpo e equilíbrio pessoal (mente/corpo), (Grupo 1, 1,7\% e Grupo 2 4,9\%), foi possível identificar outros focos e eixos temáticos associados às concepções e percepções de saúde mental dos jovens, inferindose que os jovens se utilizam de mais elementos adquiridos ao longo do desenvolvimento, como recursos, capacidades e competências a partir da interação com o ambiente e com o outro, como condicionantes principais para a concepção de saúde mental. Esse aspecto reforça a necessidade de proposição de políticas públicas com vistas à saúde integral e intervenções em saúde com essa população contemplando efetivamente aspectos biopsicossociais.

Perceberam-se nos desenhos uma maior ocorrência de construção de conceito de saúde mental focada no desenvolvimento saudável, promovida pela interação dos núcleos: processo, pessoa e contexto, sob uma perspectiva biopsicológica. As categorias Bem estar na relação com o outro; Sentimento de paz, liberdade e harmonia global; Esportes e lazer; Escola e Contextos sociais demonstram a concepção de saúde mental embasada nessa interação.

Ao comparar o significado da percepção acerca da saúde mental entre os jovens provenientes de contextos com IDH diferentes, verificaram-se poucas diferenças nas concepções de saúde mental entre jovens do contexto com alto e baixo IDH. Os jovens conceberam saúde mental permeada principalmente por aspectos subjetivos, seguida pelas relações sociais e pela interação em variados ambientes, ao longo do processo. Essas ideias aparecem de forma progressiva, na perspectiva de transição ecológica, que pode ser saudável à medida que gera competências e tem a participação de relações significativas no processo de desenvolvimento (Bronfenbrenner, 1996).

Houve concordância entre os grupos referente à categoria Bem estar consigo mesmo e autoestima como mais frequente para o significado de estar saudável mentalmente/emocionalmente. A qualificação dada pelos jovens a essa categoria demonstra a importância da pessoa nos processos proximais de desenvolvimento. A categoria envolve bem estar subjetivo, otimismo, felicidade, autoconfiança, habilidades interpessoais que são características determinadas biopsicologicamente e construídas na interação com o ambiente, ou atributos psicológicos, característico de um desenvolvimento saudável.

Ressalta-se a importância dos vínculos intrafamiliares e inter-relacionais como aspecto positivo para o desenvolvimento saudável. A família, ou ambiente familiar, como primeiro sistema (microssistema) no processo do desenvolvimento, propicia o estabelecimento de relações estáveis e significativas. Para Bronfenbrenner (1996) é importante que essas primeiras relações sejam de reciprocidade, equilíbrio de poder e afeto, o que introduz a pessoa num conjunto de outros sistemas, desenvolvendo suporte emocional como capacidade para suportar adversidades. Além disso, o adolescente constrói sua auto-imagem e reconhece-se como cidadão a partir dessas relações interpessoais percebidas como significativas (De Antoni e Koller 2000; Sudbrack \& Pereira, 2003). Para os dois grupos pesquisados, a família ficou em segundo lugar na ordem de ocorrência, estando atrás apenas de aspecto ligado à pessoa (Bem-estar consigo mesmo e auto estima), demonstrando que muitos adolescentes percebem saúde mental relacionada a esse primeiro microssistema.

As diferenças na incidência da categoria Família nos grupos provenientes de regiões com alto e baixo IDH podem ser justificadas pelo próprio nível socioeconômico dos dois grupos de jovens. Para Sudbrack (1996), no contexto de baixa renda o desenvolvimento saudável pode ficar prejudicado, pois o ambiente familiar e a formação de pares, não oferecem condições para canalização de frustrações de forma saudável. Tal dado pode refletir uma maior dificuldade de famílias de baixa renda em oferecer condições para um desenvolvimento saudável ao jovem, levando-o a considerar menos importante o papel da família na caracterização da saúde mental. Assim, considera-se que pode ter havido uma influencia do contexto socioeconômico na concepção de saúde dos jovens analisados, demonstrando a relatividade dessa concepção e a influência de fatores contextuais, o que está 
de acordo com resultados encontrados por outros autores (Flick \& Röhnsch, 2007; Minayo, 2008; Tontas, 2009).

A representação da escola como importante para a saúde mental foi pouco significativa para ambos os grupos (Grupo 1, 3,5\% e Grupo 2, 0,7\%). Além da formação cognitiva, a escola deveria ser uma fonte de proteção (Amparo, Galvão, Alves, Cardenas, \& Koller, 2008) e um ambiente que promove a formação moral e autonomia pessoal. No entanto, para Sudbrack e Pereira (2003), as escolas, principalmente as da rede pública, oferecem menos oportunidades para crianças e jovens carentes e tornam-se um fator de estresse emocional, visto que dificuldades encontradas no ambiente familiar dessas crianças e jovens são canalizadas para a escola, que muitas vezes não é capaz de acolhê-las. Quando as relações dos jovens com a escola são enfraquecidas, podem produzir experiência estressora, e o sistema de suporte social da escola pode, ao contrário de favorecer mecanismos de proteção, contribuir com o desenvolvimento de comportamentos de risco.

A categoria Contextos sociais abrange de forma variada a interação de pessoas de referência (amigos, pais, etc.) com o ambiente (tais como escola, igreja, casa) e/ou situações (emprego, lazer, atividades físicas). Essa categoria assemelha-se ao terceiro elemento do modelo ecológico: contexto. Observa-se uma ampliação do ambiente ecológico, dando-se importância à comunicação com outros grupos, bem como a natureza dos vínculos, como fator importante na percepção de saúde mental dos jovens. Da mesma forma, a categoria Sentimento de paz e liberdade, e ligados ao contexto da natureza demonstra uma preocupação sistêmica, com a interação em ambientes naturais e sociais que promovem sentimentos positivos, como significantes para a saúde mental.

A importância da experiência do bem estar, resultante de um equilíbrio dinâmico entre aspectos físicos e psicológicos, assim como as interações com o meio ambiente natural e social, das relações, do contexto e da influência dos estados afetivos na construção do conceito de saúde mental, está coerente com a teoria ecológica (Bronfenbrenner, 1986;1989;1996) e promovem desenvolvimento saudável na percepção dos jovens. Considerando essas ideias a partir da ótica do adolescente, percebe-se que a concepção coaduna com a própria fase da adolescência, que configura uma noção do $e u$ oscilando entre: capacidade de estar bem consigo mesmo, orientada pelo meio ambiente de interação; necessidade de apoio de uma rede social confiável, para promover a formação moral e autonomia pessoal: afirmação, diferenciação e identidade. Essas condições são favoráveis para experimentar a saúde, restaurando-a e evitando doenças, promovendo um desenvolvimento saudável.

\section{Conclusão}

A experiência do bem estar e a influência dos estados afetivos, as interações com o meio ambiente natural e social, os vínculos intrafamiliares e inter-relacionais e o contexto foram fundamentais para a construção do conceito de saúde mental para os adolescentes dos dois contextos socioeconômicos. Em meio às transformações biopsicossociais normativas dessa fase do desenvolvimento, observou-se que a concepção dos jovens sobre esse tema sofre influência de muitos aspectos abordados na teoria ecológica do desenvolvimento. De fato, o conceito de saúde para os jovens estudados caracterizou-se por ser multidimensional (Koller \& Morais, 2006). A evolução histórica do conceito de saúde mostra a mudança de foco, que sai do sujeito, do seu aspecto físico e biológico, em direção à sua interação com o meio, concebendo a noção de saúde os aspectos psicológicos e sociais, e não apenas um estado positivo de bem estar, como pôde ser observado nos desenhos dos jovens.

Os adolescentes pesquisados demonstraram que suas concepções de saúde mental estão baseadas tanto no bem estar pessoal quanto nos contextos sociais. Tal resultado é importante de ser reconhecido na proposição de políticas públicas para jovens e adolescentes, que deveriam considerar tais aspectos como fundamentais para um desenvolvimento saudável, ou seja, considerar que o jovem se desenvolve em interação com o ambiente e está consciente da importância dessa interação para o seu desenvolvimento. Isto reforça a importância de investigar melhor a demanda em saúde mental dos adolescentes, pois essa faixa etária se constitui como uma grande parcela da população. Além disso, o adolescente é identificado como um grupo etário vulnerável e de risco para diversas problemáticas e transtornos no campo da saúde mental (Benetti, Ramires, Schneider, Rodrigues, \& Tremarin, 2007).

Para além da compreensão do conceito de saúde mental sob a ótica dos adolescentes, a pesquisa pode reverberar em ações, de forma a contribuir para o trabalho de profissionais de saúde, para a rede de apoio do adolescente e para o próprio adolescente, que tem a oportunidade para a introspecção e a reflexão acerca de sua concepção de saúde mental, instigando-o na elaboração de atitudes positivas em relação à sua saúde. Considera-se que o método utilizado pode contribuir para pesquisas posteriores, demonstrando a possibilidade de estudar concepções a partir de desenhos.

As diferenças de idade e escolaridade entre os dois grupos de jovens que participaram da pesquisa e o uso de dois juízes para cada desenho na validação das categorias de concepções sobre saúde mental foram consideradas fatores limitantes da pesquisa. Portanto, sugere-se para pesquisas futuras, uma amostra mais equitativa entre os grupos de baixo e alto IDH, o aumento do número de juízes e, para uma compreensão mais detalhada das representações dos adolescentes e seus significados o incremento de entrevistas com os participantes sobre os significados dos desenhos feitos poderá contribuir para uma melhor exploração e investigação da temática da pesquisa.

Por fim, considera-se e que a análise de concepções de saúde mental de jovens de outras regiões brasileiras também seria importante para validar as categorias propostas e identificar outras diferenças culturais relevantes na percepção de saúde mental dos mesmos.

\section{Referências}

Amparo, D. M, Galvão, A., Alves, P., Cardenas, C., \& Koller, S. (2008). A escola e as perspectivas educacionais de jovens em situação de risco. Psicologia Escolar e Educacional, 12, 69-88.

Amparo, D. M, Galvão, A., Alves, P., Brasil, K. C. T., Cardenas, C., \& Koller, S 
(2008). Adolescentes e jovens em situação de risco psicossocial: redes de apoio social e fatores pessoais de proteção. Estudos de Psicologia (Natal), 13,165-174.

Benetti, S. P. C., Ramires, V. R. R., Schneider, A. C., Rodrigues, A. P. G., \& Tremarin, D. (2007). Adolescência e saúde mental: revisão de artigos brasileiros publicados em periódicos nacionais. Cadernos de Saúde Pública, 23(6), 1273-1282.

Boddington, P., \& Räisänen, U. (2009). Theoretical and practical issues in the definition of health: insights from aboriginal Australia. Journal of Medicine and Philosophy, 34, 49-67.

Bolsoni-Silva, A., Villas Boas, A., Romera, V., \& Silveira, F. (2010). Caracterização de programas de intervenção com crianças e/ou adolescentes. Arquivos Brasileiros de Psicologia, 62(1), 104-118.

Boruchovitch, E., \& Mednick, B. R. (2002). The meaning of health and illness: some considerations for health psychology. Psico-USF, 7(2), 175-183.

Brasil, K., Alves, P., Amparo, D. M., \& Frajorge, K. (2006) Fatores de risco na adolescência: discutindo dados do DF. Paideia, 16, 377-384.

Bronfenbrenner, U. (1986). Ecology of the family as a context for human development: research perspectives. Developmental Psychology, 22, 723 742 .

Bronfenbrenner, U. (1989). Ecological systems theory. In R.Vasta (Org.), Annals of Child Development (vol. 6) (pp. 187-249). Greenwich, CT: JAI Press.

Bronfenbrenner, U. (1996). A ecologia do desenvolvimento humano: experimentos naturais e planejados. Porto Alegre: Artes Médicas.

De Antoni, C., \& Koller, S.H.(2000). A visão de família entre as adolescentes que sofreram violência intrafamiliar. Estudos de Psicologia (Natal), 5(2), 347-381.

Flick, U., \& Röhnsch, G. (2007). Idealization and Neglect: health concepts of homeless Adolescents. Journal of Health Psychology, 12, 737-749.

Flick, U. (2000). Qualitative inquiries into social representations of health. Journal of Health Psychology, 5, 315-324.

Goldberg, L. G., Yunes, M. A. M., \& Freitas, J. V. (2005). O desenho infantil na ótica da Ecologia do Desenvolvimento Humano. Psicologia em Estudo, 10(1), 97-106.

Heilborn, M. L., Salem. T., Rohden, F., Brandão, E., Knauth, D., Víctora. C, ... Bozon, M. (2002). Aproximações socioantropológicas sobre a gravidez na adolescência. Horizontes Antropológicos, 8(17), 13-45. doi:10.1590/S010471832002000100002

Jones, C. J., \& Peskin, H. (2010). Psycological health from the teens to the 80s: multiple developmental trajectories. Journal of Adult Development, $17,20-32$.

Kaplan, H. I., \& Sadock, B. J. (1984). Teorias da personalidade e psicopatologia: outras Escolas. In H. I. Kaplan \& B. J. Sadock (Orgs.), Compêndio de Psiquiatria Dinâmica (pp. 137-139). Porto Alegre: Artes Médicas.
Koller, S. H., \& Morais, N. A. (2004). Abordagem ecológica do desenvolvimento humano, Psicologia Positiva e resiliência: ênfase na Saúde. In S. H. Koller (Org.), Ecologia do Desenvolvimento Humano: Pesquisa e Intervenção no Brasil (pp. 91-103). São Paulo: Casa do Psicólogo.

Koller, S. H., \& Morais, N. A. (2006). Uma abordagem ecológica de saúde para o desenvolvimento humano. In M. H Freitas \& M. A Ribeiro (Orgs.), Psicopatologia, processos de adoecimento e promoção da saúde (pp. 6985). Brasília: Universa.

Marques, A. C., \& Cruz, M. S. (2000) O adolescente e o uso de drogas. Revista Brasileira de Psiquiatria, 22(2), 32-36.

Minayo, M. C. S. (2008). O desafio do conhecimento: pesquisa qualitativa em saúde. $11^{\underline{a}}$ ed. São Paulo: Hucitec.

Morais, C. A. (2008). Saúde, doença mental e serviços de saúde na visão de adolescentes e seus cuidadores. (Dissertação de Mestrado). Universidade Federal do Rio Grande do Sul.

Moreira, A. A. A. (2008). O desenho da criança. In A. A. A. Moreira (Org.), O espaço do desenho: a educação do educador (pp. 15-36). São Paulo: Loyola.

Oliver, S., Hardeb, A., Rees, R., Shepherd, J., Bruton, G., \& Oakley, A. (2008). Young people and mental health: novel methods for systematic review of research on barriers and facilitators. Health Education Research, 23(5), 770-790.

Pereira, A. C. A. (2005). O Adolescente em desenvolvimento. São Paulo: Harbra.

Pesce, R., Assis, S., Santos, N., \& Oliveira, N. (2005). Risco e proteção: em busca de um equilíbrio promotor de resiliência. Psicologia: Teoria e Pesquisa, 20(2), 135-143.

Pietro, D., \& Tavares, M. (2005). Fatores de risco para suicídio e tentativa de suicídio: incidência, eventos estressores e transtornos mentais. Jornal Brasileiro de Psiquiatria, 54(2), 146-154

Piko, F., \& Bak, J. (2006). Children's perceptions of health and ilness: images and lay concepts in preadolescence. Health Education Research, 21, 643-653.

Richter, L. M. (2006). Studying Adolescence. Science, 312, 1902-1905.

Sudbrack, M. F. O. (1996). Construindo redes sociais: metodologia de prevenção à drogadição e à marginalização de adolescentes de famílias de baixa-renda. In R. M. Macedo (Org.), Família e Comunidade (Coletâneas da ANPEPP, 2, pp. 87-113). Rio de Janeiro: Associação Nacional de Pesquisa e Pósgraduação em Psicologia.

Sudbrack, M. F. O., \& Pereira, S. E. F. N. (2003). Avaliação das redes sociais de adolescentes em situação de risco. In M. F. O. Sudbrack (Org.), O adolescente e as drogas no contexto da justiça (pp. 166-171). Brasília: Plano Editora.

Tontas, Y. (2009). The historical origins of the basic concepts of health promotion and education: the role of ancient Greek philosophy and medicine. Health Promotion International, 24(2), 185-192.

Yunes, M. A. M. (2003). Psicologia positiva e resiliência: o foco no indivíduo e na família. Psicologia em Estudo, 8, 75-84.

Cláudia Cristina Fukuda, doutora em Psicologia pela Universidade de Brasília, é professora da Universidade de Brasília do Programa Pós-Graduação Stricto Sensu em Psicologia. Endereço para correspondência: SHIN QL 07, conjunto 07, casa 15. Lago Norte. Brasília - DF. CEP: 71515-075. Telefones: (61) 33446820 (res.); (61) 99782416 (cel.); (61) 34487204 (trab.). E-mail: fukuda@ucb.br

Karolyne Araújo Garcia, especialista em Psicologia Clinica com Formação em Saúde Mental, é psicóloga da Secretaria de Estado de Saúde, Hospital São Vicente de Paulo - Distrito Federal. E-mail: karolyne_ag@ yahoo.com.br

Deise Matos do Amparo, doutora em Psicologia pela Universidade de Brasília e pós-doutora pela Université Paris Decartes, é professora da Universidade de Brasília do Programa de Pós-Graduação em Psicologia Clínica e Cultura, e bolsista Produtividade CNPq. E-mail: deiseamparo@unb.br 